\title{
Unintentionally doped epitaxial 3C-SiC(111) nanothin film as material for highly sensitive thermal sensors at high temperatures
}

\author{
Toan Dinh, Hoang-Phuong Phan, Tuan-Khoa Nguyen, Vivekananthan Balakrishnan, Han-Hao Cheng, Leonie \\ Hold, Alan Lacopi, Nam-Trung Nguyen, Dzung Viet Dao,
}

\begin{abstract}
There is a growing interest and demand to develop sensors that operate at high temperatures. In this work, we investigate the temperature sensing properties of unintentionally doped n-type single crystalline cubic silicon carbide (3C-SiC) for high temperatures up to $800 \mathrm{~K}$. A highly sensitive temperature sensor was demonstrated with a temperature coefficient of conductivity (TCC) ranging from $1.96 \times 10^{4}$ to $5.18 \times 10^{4} \mathrm{ppm} / \mathrm{K}$. The application of this material was successfully demonstrated as a hot film flow sensor with its high signal-to-noise response to air flow at elevated temperatures. The high TCC of the single crystalline $\mathrm{SiC}$ film at, and above $800 \mathrm{~K}$ strongly revealed its potential for highly sensitive thermal sensors working at high temperatures.
\end{abstract}

Index Terms-Silicon carbide, temperature effect, thermal sensors, heater.

\section{INTRODUCTION}

$\mathbf{S}$ INCE The growing demand for sensors and electronic circuits operating at high temperatures has inspired recent research on discovering novel and unprecedented wide band gap materials for a wide range of applications [1], [2]. High temperature sensing applications include, but are not limited to, health monitoring of instrumentation systems in oil and gas investigation and deep space exploration [3], where the temperature is ranging from 600 to above $800 \mathrm{~K}$. These applications require the reliability and high sensitivity of sensing materials. However, conventional materials used for thermal sensors including silicon and metals are not reliable when operating at high temperatures due to the degradation of their mechanical and electrical properties, and low sensitivity with a temperature coefficient [4] typically below $7 \times 10^{3} \mathrm{ppm} / \mathrm{K}$.

Recently, silicon carbide $(\mathrm{SiC})$ has been demonstrated as a promising material for high temperature sensing applications, owing to its large band gap, superior mechanical and electrical properties, and chemical inertness [5], [6], [7]. In addition, the successful demonstration of low-cost high-quality single crystalline $\mathrm{SiC}$ grown on large-area $\mathrm{Si}$ wafers has indicated the future development of highly sensitive $\mathrm{SiC}$ physical sensors working at high temperatures [8]. For example, recent studies have investigated the relatively large strain and temperature effects on SiC devices [9], [10], [11], [12]. However, the $\mathrm{SiC}$ on $\mathrm{Si}$ platform is not favourable for high temperature applications as unwanted electrical influence from the $\mathrm{Si}$ conducting substrate creates a great challenge for electrical

T. Dinh, H.-P. Phan, T.-K. Nguyen, V. Balakrishnan, L. Hold, A. Lacopi, N.-T. Nguyen and D. V. Dao are with the Queensland MicroNanotechnology Centre, Griffith University, Nathan QLD 4111, Australia (email: toan.dinh@griffithuni.edu.au).

H.-H. Cheng is with Centre for Microscopy and Microanalysis, The University of Queensland, Queensland, Australia characterisation of $\mathrm{SiC}$ devices [13], [14]. Consequently, the thermoresistive properties of epitaxial $\mathrm{SiC}$ at high temperatures (e.g. 500 to above $800 \mathrm{~K}$ ) have not been fully understood.

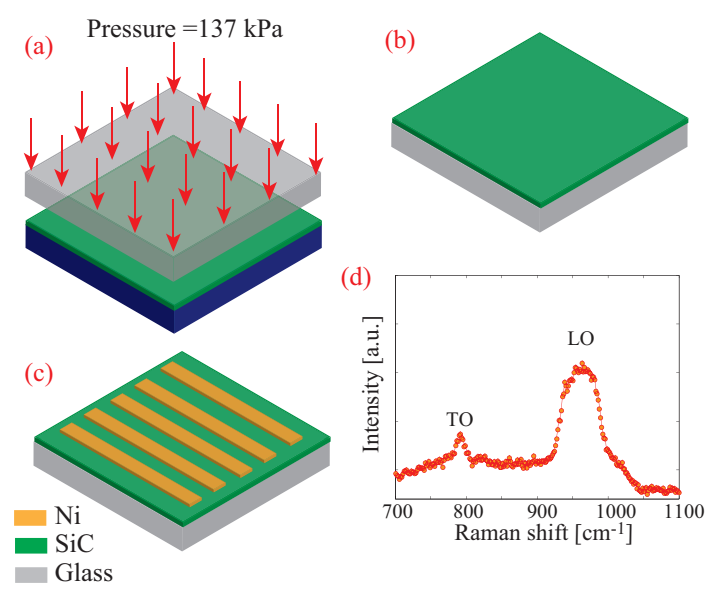

Fig. 1. Fabrication of $\mathrm{SiC}$ samples: (a) Bonding of $\mathrm{SiC} / \mathrm{Si}$ on glass; (b) Removal of Si to form SiC on glass; (c) Patterned metal electrodes; (d) Raman spectral of $\mathrm{SiC}$.

In addition, only a limited number of studies have been conducted to investigate the thermoresistive properties of $\mathrm{SiC}$ and its applications for thermal sensors [13], [15], [16], [17]. However, either the sensitivity of $\mathrm{SiC}$ thermal sensors is low [16], or its application is limited [13], [15], [17] due to the lack of its self-heating capability at low supplying power. Therefore, there is a great demand for understanding the electrical properties of $\mathrm{SiC}$ at high temperatures, and developing highly sensitive, low-power consumption thermal sensors working in high temperature environments.

In the current work, we investigate the thermoresistive properties of unintentionally doped n-type single crystalline nanoscale 3C-SiC films for a wide temperature range from 300 to above $800 \mathrm{~K}$. The $\mathrm{SiC}$ material showed an extremely high sensitivity to temperature variation with a temperature coefficient of conductivity (TCC) ranging from $1.96 \times 10^{4}$ to $5.18 \times 10^{4} \mathrm{ppm} / \mathrm{K}$. The material can also be self-heated to high temperatures under low supply power densities, and able to detect air flow at elevated temperatures with a high signal-tonoise ratio.

\section{EXPERIMENTAL}

Employing low pressure chemical vapour deposition (LPCVD) at a temperature of $1000^{\circ} \mathrm{C}$, single crystalline cubic silicon carbide films were grown on a 6-inch (111) $\mathrm{Si}$ substrate. $\mathrm{SiH}_{4}$ and $\mathrm{C}_{3} \mathrm{H}_{6}$ were used as alternating precursors in the epitaxy growth process. The material was standard 

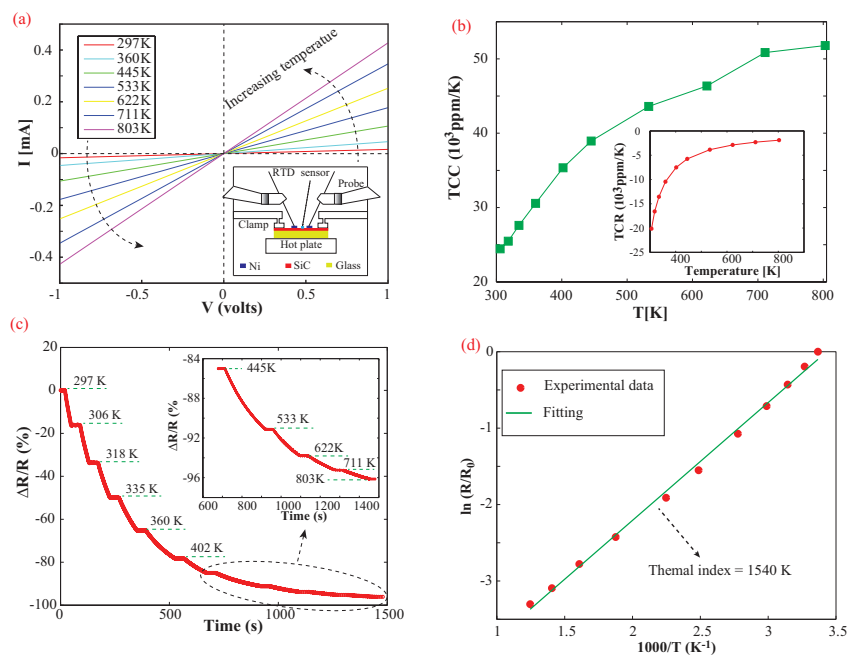

Fig. 2. Thermoresistive effect in $\mathrm{SiC}$ at high temperatures: (a) Current-voltage characteristics at various temperatures; (b) Temperature coefficient of conductivity (TCC). The inset shows the temperature coefficient of resistance (TCR); (c) Real-time response of the $\mathrm{SiC}$ resistance with temperature variation. The inset shows the close-up graph of $\mathrm{SiC}$ real-time response to temperatures above $445 \mathrm{~K}$; (d) Arrhenius plot of $\mathrm{SiC}$ thermoresistance.

unintentionally doped n-type $\mathrm{SiC}$ on $\mathrm{Si}$ provided by the the Queensland Microtechnology Facility (QMF) at Griffith University, Australia.

The 6 inch wafer of as-grown $\mathrm{SiC}$ nanoscale films on $\mathrm{Si}$ was then bonded to a glass wafer (Borofloat 33, University Wafers) using an Plasma enhanced anodic bonding process (Figure 1a) at a maximum pressure of $137 \mathrm{kPa}$ and bias voltage of 1000 volts. In the next step, the Si layer was removed using mechanical polishing and a subsequent wet etching process (using a solution of $\mathrm{HF}, \mathrm{HNO}_{3}$ and $\mathrm{CH}_{3} \mathrm{COOH}$ with a ratio of $2: 2: 3$ ). Figure $1 \mathrm{~b}$ shows the schematic sketch of the $\mathrm{SiC}$ on the glass platform. To form the $\mathrm{SiC}$ resistors on glass, nickel (Ni) with a thickness of $200 \mathrm{~nm}$ was first deposited on the $\mathrm{SiC} /$ glass platform using a sputtering process. Standard photolithography and wet etching processes were then employed to pattern Ni electrodes (Figure 1c). The resistivity of the $\mathrm{SiC}$ films was measured to be approximately $5.7 \Omega \mathrm{cm}$ and the carrier concentration was estimated to be about $10^{16} \mathrm{~cm}^{-3}$. The thickness of the SiC films was found to be approximately 300 nm using NANOMETRICS Nanospec AFT 210. In addition, the Raman spectrum (Figure 1d) indicates two predominant peaks at wavenumbers of 797 and $965 \mathrm{~cm}^{-1}$, corresponding to the transverse optic (TO) mode and longitudinal optic (LO) mode of 3C-SiC material [18], [19], respectively. The detail chacterisation of the $\mathrm{SiC}$ material has been reported previously elsewhere [20], [21]. The electrical characterisation of the $\mathrm{SiC}$ device was performed in an enclosed chamber with a Linkam HFS600E-PB4 hot plate (the inset of Figure 2a shows the schematic sketch of the experimental setup), while the temperature of the device was calibrated using RTD (Resistance temperature detector).

\section{RESULTS AND DISCUSSION}

Figure $2 \mathrm{a}$ shows the linear current-voltage characteristics of the $\mathrm{SiC}$ films measured at various temperatures ranging from 300 to above $800 \mathrm{~K}$. It is evident that the measured current increases from $I_{o}=16.2 \mu \mathrm{A}$ to $I=427.35 \mu \mathrm{A}$ at a constant voltage of $1 \mathrm{~V}$ when the temperature increased from $300 \mathrm{~K}$ to $800 \mathrm{~K}$, indicating that the conductivity of $\mathrm{SiC}$ films is thermally activated. The temperature coefficient of conductivity (TCC) can be calculated as following:

$$
T C C=\frac{\Delta \sigma}{\sigma_{o}} \times \frac{1}{\Delta T}=\frac{I-I_{o}}{I_{o}} \times \frac{1}{\Delta T}
$$

where $\Delta \sigma / \sigma_{o}$ and $\Delta T$ are the conductivity change and temperature change, respectively. Figure $2 \mathrm{~b}$ shows the dependence of the TCC on temperature variation. It is obvious that the TCC value increased 2.65 times from $1.96 \times 10^{4} \mathrm{ppm} / \mathrm{K}$ at $25^{\circ} \mathrm{C}(\sim 300 \mathrm{~K})$ to $5.18 \times 10^{4} \mathrm{ppm} / \mathrm{K}$ at a temperature of 800 $\mathrm{K}$. This temperature sensitivity exceeds that of conventional materials used for heating-based thermal sensors (e.g. thermal flow sensors and convective inertial sensors), including metals and highly doped silicon [4], [22], [23]. This result is of high interest for developing highly sensitive thermal sensors. It is important to note that the difference of thermal expansion between $\mathrm{SiC}$ film, electrodes and glass substrate has a minor impact on the measured TCC and can be neglected [4].

Based on the linear characteristics of the $\mathrm{SiC}$ in Figure $2 \mathrm{a}$, the electrical resistance of $\mathrm{SiC}$ films can be defined by Ohm law $\mathrm{R}=\mathrm{V} / \mathrm{I}$. The relative resistance change $\Delta R / R$ under different applied temperatures is presented in Figure 2c. It is important to note that the sensor was calibrated with a ramp up rate of 15 to $30^{\circ} \mathrm{C} / \mathrm{min}$ and a holding time of 2 minutes for each measurement. The electrical characteristic of the $\mathrm{SiC}$ on glass platform was reversible. The dependence of $\mathrm{SiC}$ electrical properties on temperature can be alternatively quantified using temperature coefficient of resistance (TCR) as $\mathrm{TCR}=\Delta R / R \times 1 / \Delta T=-T C C /(T C C \times \Delta T+1)$. The corresponding TCR of the $\mathrm{SiC}$ material is approximately $20,000 \mathrm{ppm} / \mathrm{K}$ at $300 \mathrm{~K}$ (The inset of Figure $2 \mathrm{~b}$ ). Since the $\mathrm{SiC}$ material has a very high TCR at room temperatures, it can also be employed as a sensitive robust temperature sensor for harsh environments at ambient temperatures. The sensing mechanism of the $\mathrm{SiC}$ material is discussed as follows.

The temperature dependence of $\mathrm{SiC}$ conductivity is attributed to the variation of its electron concentration and electron mobility. The electron mobility can be described as $\mu=\left(1 / \mu_{l}+1 / \mu_{i}\right)^{-1}$, where $\mu_{l}$ and $\mu_{i}$ are the mobilities from scattering of lattice and ionized impurities, respectively [24], [25]. As the material is unintentionally doped, the mobility from ionized impurities is negligible at the temperature range of 300 to above $800 \mathrm{~K}$. In addition, due to the increase of acoustic phonon scattering of the lattice at elevated temperatures, we hypothesise that the electron mobility from lattice scattering decreases with increasing temperature [25], [26] $\mu_{l} \sim T^{-\alpha}$, where $\alpha$ is an experimental constant. Since single crystalline $3 \mathrm{C}-\mathrm{SiC}$ has high crystal symmetry, the contribution of the intervalley scattering could be low [26], [27] ( $\alpha=1.2$ to 1.4), and hence the temperature dependence of the $\mathrm{SiC}$ electron mobility is insignificant. On the other hand, the electron concentration is hypothesized to increase with increasing applied thermal energy [24], [25] (kT) as $n \sim T^{\alpha} \exp \left(-E_{a} / k T\right)$, where $E_{a}$ and $k$ are the activation energy of carriers and the Boltzmann constant, respectively. As the SiC nanofilms were grown on [111] orientation, crystal defects and stacking faults 

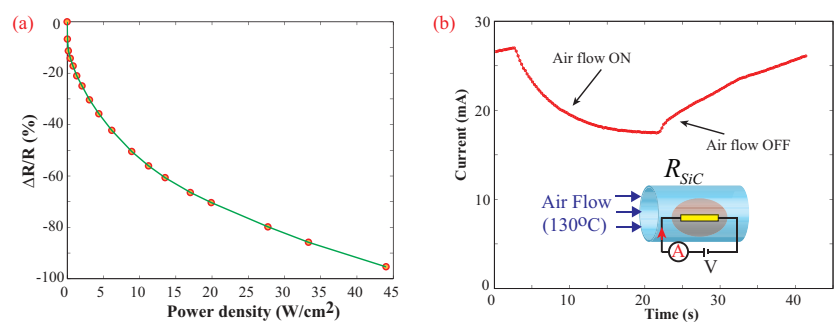

Fig. 3. Demonstration of the $\mathrm{SiC}$ nanoscale film for flow sensing at elevated temperatures. (a) Self-heating effect in the $\mathrm{SiC}$ nano films at low supply power density: Resisance change vs supply power density. (b) Response of the $\mathrm{SiC}$ hot film to air flow at elevated temperatures. The inset shows the schematic sketch of experimental setup with measurement method.

could exist through out the thickness of the films [20], [28], which can trap free electrons. These trapped electrons become active under supply thermal energy at elevated temperatures. Therefore, the conductivity $\sigma$ of the $\mathrm{SiC}$ material increases with increasing temperature, which is described as follows:

$$
\sigma \sim \exp \left(\frac{-E_{a}}{k T}\right)
$$

This indicates the positive large temperature coefficient of conductivity presented in the inset of Figure $2 \mathrm{~b}$. For temperature sensing, the $\mathrm{SiC}$ nanofilm can be used as a resistive temperature detector (RTD) with its resistance extrapolated from Equation 2 as $R=R_{0} \exp \left(B\left(1 / T-1 / T_{0}\right)\right)$, where $R_{0}$ is the $\mathrm{SiC}$ resistance at reference temperature $T_{0}$, and $B=E_{a} / k$ is the thermal index of the $\mathrm{SiC}$ nanofilm. Therefore, the relationship between the resistance change and temperature can be described in the following form:

$$
\ln \left(R / R_{0}\right)=\frac{B}{T}-A
$$

where $A=B / T_{0}$ is a constant. Based on Equation 3, the thermoresistance of the $\mathrm{SiC}$ material is plotted in Figure $2 \mathrm{~d}$ using Arrhenius law. The thermal index was extracted to be approximately $1540 \mathrm{~K}$, which is comparable with the performance of the highly sensitive flexible/stretchable graphenebased thermistor recently reported [29], [30]. This indicates the potential of using the $\mathrm{SiC}$ nanofilm as a highly sensitive RTD sensor for high temperature sensing applications.

The self heating capability of SiC film needs to be investigated as it refers to the efficiency of the Joule heating effect to rise the temperature of the heating component with low power density/consumption and low supply voltage/current. To observe the self-heating characteristics of the $\mathrm{SiC}$ material, different supply powers were applied to the $\mathrm{SiC}$ device while its electrical resistance was measured. Since the $\mathrm{SiC}$ device is constructed on the glass substrate, the power density distributing on the device can be assumed as $P_{D}=P / A$, where $P_{D}$ and $A$ are the power consumption and convection area, respectively. Figure 3 a shows the resistance change of the $\mathrm{SiC}$ device under various applied power densities. At a low supply power density of $20 \mathrm{~W} / \mathrm{cm}^{2}$, the temperature of the hot nanofilm reached $100^{\circ} \mathrm{C}$ (not shown here). To achieve the self heating capability at low power density and supply voltage/current, the thickness of the SiC film should be selected for a reasonable electrical resistance depending upon the resistivity of the film.

To demonstrate the use of this material for high temperature sensors, we supplied a power density of $35 \mathrm{~W} / \mathrm{cm}^{2}$, corresponding to a temperature of approximately $300^{\circ} \mathrm{C}$ rising on the nanofilm, and measured the response of the hot film sensor under the application of air flow at an elevated temperature. Figure $3 \mathrm{~b}$ shows the current response of the $\mathrm{SiC}$ hot film flow sensor under the air flow at an air temperature of $130^{\circ} \mathrm{C}$. It is evident that the measured current decreased significantly with the applied air flow, and returned the initial value when the air flow rate returned to zero. This is because the air flow cooled down the heater which exhibits the positive TCC, leading to a decrease in the electrical conductivity of the SiC film. The high signal-to-noise ratio indicates the high potential of using the $\mathrm{SiC}$ material for highly sensitive flow sensing devices at high temperatures. However, the response of this platform is quite slow (Figure 3b). To achieve a fast response of the thermal sensors employing this material, it is recommended to isolate the $\mathrm{SiC}$ material from the glass by etching glass to make cavities before bonding of $\mathrm{SiC}$ on glass.

\section{CONCLUSION}

In conclusion, we investigated the sensing properties of $\mathrm{SiC}$ nanofilms at high temperatures with a high temperature coefficient of conductivity of up to $5.18 \times 10^{4} \mathrm{ppm} / \mathrm{K}$ for temperatures of up to $800 \mathrm{~K}$. The $\mathrm{SiC}$ material was also successfully demonstrated as a hot film flow sensor for air flow monitoring at elevated temperatures with a high signalto-noise ratio, indicating its wide range applications for high temperature sensing devices. We believe the unprecedented thermoresistive properties of the $\mathrm{SiC}$ material will provide new opportunities for developing highly sensitive sensors working in high temperatures of at, and above, $800 \mathrm{~K}$.

\section{ACKNOWLEDGMENT}

This work was performed in part at the Queensland node of the Australian National Fabrication Facility, a company established under the National Collaborative Research Infrastructure Strategy to provide nano and micro-fabrication facilities for Australia's researchers. This work has been partially supported by Australian Research Council grants LP150100153 and LP160101553.

\section{REFERENCES}

[1] V. Cimalla, J. Pezoldt, and O. Ambacher, "Group III nitride and SiC based MEMS and NEMS: materials properties, technology and applications," Journal of Physics D: Applied Physics, vol. 40, p. 6386, Oct. 2007, doi: 10.1088/0022-3727/40/20/S19.

[2] N. Zhang, C.-M. Lin, D. G. Senesky, and A. P. Pisano, "Temperature sensor based on $4 \mathrm{H}$-silicon carbide pn diode operational from $20 \mathrm{C}$ to 600 C," Applied Physics Letters, vol. 104, p. 073504, Feb. 2014, doi:10.1063/1.4865372.

[3] D. G. Senesky, B. Jamshidi, K. B. Cheng, and A. P. Pisano, "Harsh environment silicon carbide sensors for health and performance monitoring of aerospace systems: A review," IEEE Sensors Journal, vol. 9, pp. 14721478, Nov. 2009, doi: 10.1109/JSEN.2009.2026996.

[4] T. Dinh, H.-P. Phan, A. Qamar, P. Woodfield, N.-T. Nguyen, and D. V. Dao, "Thermoresistive effect for advanced thermal sensors: Fundamentals, design considerations, and applications," Journal of $\mathrm{Mi}$ croelectromechanical Systems, Vol. 26, pp.966-986, Oct. 2017, doi: 10.1109/JMEMS.2017.2710354. 
[5] J. Casady and R. W. Johnson, "Status of silicon carbide (SiC) as a wide-bandgap semiconductor for high-temperature applications: A review,' Solid-State Electronics, vol. 39, pp. 1409-1422, Oct. 1996, doi: 10.1016/0038-1101(96)00045-7.

[6] X. Huang, K. Ekinci, Y. Yang, C. Zorman, M. Mehregany, and M. Roukes, "Nanoelectromechanical silicon carbide resonators for ultra-high frequency applications," in Proc. 2002 Sensor, Actuator and Microsystems Workshop, Jun. 2002, pp. 2-6.

[7] H.-P. Phan, T. Dinh, T. Kozeki, T.-K. Nguyen, A. Qamar, T. Namazu, N.-T. Nguyen, and D. V. Dao, "The Piezoresistive Effect in TopDown Fabricated p-Type 3C-SiC Nanowires," IEEE Electron Device Letters, vol. 37, pp. 1029-1032, Aug. 2016, doi: 10.1109/LED.2016.2579020.

[8] L. Wang, S. Dimitrijev, J. Han, A. Iacopi, L. Hold, P. Tanner, and H. B. Harrison, "Growth of 3CSiC on 150-mm Si (100) substrates by alternating supply epitaxy at 1000 C," Thin Solid Films, vol. 519, pp. 6443-6446, Jul. 2011, doi: 10.1016/j.tsf.2011.04.224.

[9] J. Bi, G. Wei, L. Wang, F. Gao, J. Zheng, B. Tang, and W.Yang, "Highly sensitive piezoresistance behaviors of n-type $3 \mathrm{C}-\mathrm{SiC}$ nanowires," Journal of Materials Chemistry C, vol. 1, pp. 4514-4517, June. 2013, doi: 10.1039/C3TC30655K.

[10] T.-K. Nguyen, H.-P. Phan, T. Dinh, J. Han, S. Dimitrijev, P. Tanner, A. R. Md Foisal, Y. Zhu, N.-T. Nguyen, and D. V. Dao, "Experimental Investigation of Piezoresistive Effect in p-type 4H-SiC," IEEE Electron Device Letters, vol. 38, pp.955-958, May. 2017, doi: 10.1109/LED.2017.2700402.

[11] T. Dinh, D. V. Dao, H.-P. Phan, L. Wang, A. Qamar, N.-T. Nguyen, P. Tanner and M. Rybachuk, "Charge transport and activation energy of amorphous silicon carbide thin film on quartz at elevated temperature," Applied Physics Express, vol. 8, p. 061303, May. 2015, doi: 10.7567/APEX.8.061303.

[12] D. V. Dao, H.-P. Phan, A. Qamar, and T. Dinh, "Piezoresistive effect of p-type single crystalline 3CSiC on (111) plane," RSC Advances, vol. 6, pp. 21302-21307, Feb. 2016, doi: 10.1039/C5RA28164D.

[13] C. Dezauzier, N. Becourt, G. Arnaud, S. Contreras, J. Ponthenier, J. Camassel, J. L. Robert, J. Pascual, and C.Jaussaud, "Electrical characterization of $\mathrm{SiC}$ for high-temperature thermal-sensor applications," Sensors and Actuators A: Physical, vol. 46, pp. 71-75, Jan. 1995, doi: 10.1016/0924-4247(94)00864-E.

[14] M. Yamanaka and K. Ikoma, "Temperature dependence of electrical properties of 3C-SiC (1 11 1) heteroepitaxial films," Physica B: Condensed Matter, vol. 185, pp. 308-312, Apr. 1993, doi: 10.1016/09214526(93)90252-2

[15] V. Balakrishnan, H.-P. Phan, T. Dinh, D. V. Dao, and N.-T. Nguyen, "Thermal Flow Sensors for Harsh Environments," Sensors, vol. 17, p. 2061, Sep. 2017, doi: 10.3390/s17092061.

[16] H. Matsuura, M. Komeda, S. Kagamihara, H. Iwata, R. Ishihara, "Dependence of acceptor levels and hole mobility on acceptor density and temperature in Al-doped p-type 4H-SiC epilayers," Journal of Applied Physics, vol. 96, pp. 2708-2715, Sep. 2004, doi: 10.1063/1.1775298.

[17] C. Lyons, A. Friedberger, W. Welser, G. Muller, G. Krotz, and R. Kassing, "A High-speed mass flow sensor with heated silicon carbide bridges," in Micro Electro Mechanical Systems, 1998. MEMS 98. Proceedings., The Eleventh Annual International Workshop on, Jan. 1998, pp. 356-360, doi: 10.1109/MEMSYS.1998.659782.

[18] H. Mukaida, H. Okumura, J. Lee, H. Daimon, E. Sakuma, S. Misawa, K. Endo, and S. Yoshida, "Raman scattering of SiC: Estimation of the internal stress in 3CSiC on Si," Journal of applied physics, vol. 62, pp. 254-257, Jul. 1987, doi: 10.1063/1.339191.

[19] M. Wieligor, Y. Wang, and T. Zerda, "Raman spectra of silicon carbide small particles and nanowires," Journal of Physics: Condensed Matter, vol. 17, p. 2387, Apr. 2005, doi: 10.1088/0953-8984/17/15/010.

[20] A. Qamar, D. V. Dao, J. Han, H.-P. Phan, A. Younis, P. Tanner, T. Dinh, L. Wang, and S. Dimitrijev, "Pseudo-Hall effect in single crystal 3C-SiC (111) four-terminal devices," Journal of Materials Chemistry C, vol. 3, pp. 12394-12398, Nov. 2015, doi: 10.1039/C5TC02984H

[21] H.-P. Phan, H.-H. Cheng, T. Dinh, B. Wood, T.-K. Nguyen, F. Mu, H. Kamble, R. Vadivelu, G. Walker, L. Hold, A. Lacopi, D. V. Dao, M. Lobino, T. Suga, and N.-T. Nguyen, "Single-Crystalline 3C-SiC anodically Bonded onto Glass: An Excellent Platform for High-Temperature Electronics and Bioapplications," ACS applied materials \& interfaces, vol. 9, pp. 27365-27371, Aug. 2017, doi: 10.1021/acsami.7b06661.

[22] J. T. Kuo, L. Yu, and E. Meng, "Micromachined thermal flow sensorsA review," Micromachines, vol. 3, pp. 550-573, Jul. 2012, doi: 10.3390/mi3030550.

[23] M. S. Raman, T. Kifle, E. Bhattacharya, and K. Bhat, "Physical model for the resistivity and temperature coefficient of resistivity in heavily doped polysilicon," IEEE Transactions on Electron Devices, vol. 53, pp. 1885-1892, Aug. 2006, doi: 10.1109/TED.2006.878020.

[24] S. O. Kasap, Principles of electronic materials and devices: McGrawHill, Jan. 2006.

[25] S. M. Sze and K. K. Ng, Physics of semiconductor devices: John wiley \& sons, Nov. 2006.

[26] M. Yamanaka, H. Daimon, E. Sakuma, S. Misawa, and S. Yoshida, "Temperature dependence of electrical properties of nand ptype 3CSiC," Journal of applied physics, vol. 61, pp. 599-603, Jan. 1987, doi: 10.1063/1.338211.

[27] K. Sasaki, E. Sakuma, S. Misawa, S. Yoshida, and S. Gonda, ”Hightemperature electrical properties of $3 \mathrm{CSiC}$ epitaxial layers grown by chemical vapor deposition," Applied physics letters, vol. 45, pp. 72-73, Jul. 1984, doi: $10.1063 / 1.94973$.

[28] X. Song, J. Michaud, F. Cayrel, M. Zielinski, M. Portail, T. Chassagne, E. Collard, and D. Alquier, "Evidence of electrical activity of extended defects in 3CSiC grown on Si," Applied Physics Letters, vol. 96, p. 142104, Apr. 2010, doi: 10.1063/1.3383233.

[29] C. Yan, J. Wang, and P. S. Lee, "Stretchable graphene thermistor with tunable thermal index," ACS nano, vol. 9, pp. 2130-2137, Feb. 2015, doi: $10.1021 / \mathrm{nn} 507441 \mathrm{c}$.

[30] D. Kong, L. T. Le, Y. Li, J. L. Zunino, and W. Lee, "Temperaturedependent electrical properties of graphene inkjet-printed on flexible materials," Langmuir, vol. 28, pp. 13467-13472, Sep. 2012, doi: 10.1021/la301775d. 